\title{
APPLICATIONS OF MINIATURIZED AND PORTABLE NEAR INFRARED (NIR), FOURIER TRANSFORM INFRARED (FT-IR) AND RAMAN SPECTROMETERS FOR THE INSPECTION AND CONTROL OF PHARMACEUTICAL PRODUCTS
}

\author{
MINYATÜRE EDILMIŞ VE PORTATIF YAKIN KIZIL ÖTESİ (NIR), FOURIER \\ DÖNÜŞÜMLÜ KIZILÖTESİ (FTIR) ve RAMAN SPEKTROMETRELERININN \\ FARMASÖTIKLERIN DENETIMİ VE KONTROLÜNDEKİ UYGULAMALARI
}

\begin{abstract}
Abdullahi Garba USMAN ${ }^{1}$, Umar Muhammad GHALI ${ }^{2}$, Selin IŞIK ${ }^{1 *}$
${ }^{1}$ Department of Analytical Chemistry, Faculty of Pharmacy, Near East University, 99138, Nicosia, North Cyprus, Mersin-10 Turkey

${ }^{2}$ Department of Medical Biochemistry, Faculty of Medicine, Near East University, 99138, Nicosia, North Cyprus, Mersin-10 Turkey
\end{abstract}

\begin{abstract}
Objective: In this review, the wide range of different applications of portable and miniaturized Fourier transform infrared (FT-IR), near-infrared (NIR), and Raman spectrometers for quality control, assessment and inspection of pharmaceutical products are discussed. In regard to counterfeiting, these portable spectrometers are utilized for vibrational and scattering spectroscopies in the identification of counterfeits, adulterated, fraudulent, falsified and substandard pharmaceutical products which are becoming significant problems and a danger to general well-being, particularly in the developing nations.

Material and Method: Different scientific articles and books were researched and reviewed to explain the applications of miniaturized and portable near infrared (NIR), Fourier transform Infrared (FT-IR) and Raman spectrometers for the inspection and control of pharmaceutical products from past to nowadays.

Result and Discussion: Adulterated pharmaceutical products have become the greatest threat for developing countries. This problem can reduce the confidence for pharmaceutical products. The application of mentioned portable devices for determinations the quality control of pharmaceutical product, enables the techniques to be more accessible, quick, accurate, simple, precise, robust and more importantly, efficient.
\end{abstract}

\footnotetext{
* Corresponding Author / Sorumlu Yazar: Selin Işık e-mail: selin_isikk@hotmail.com

Submitted/Gönderilme: 18.08.2019 Accepted/Kabul: 22.12.2019
} 
Keywords: Infrared (NIR) and Raman spectrometers, Pharmaceutical products, Portable Fourier Transform Infrared (FT-IR), Quality control.

\section{ÖZ}

Amaç: Bu derlemede, farmasötik ürünlerin kalite kontrollerinin değerlendirilmesi ve belirlenmesi için portatif ve minyatür Fourier transform infrared (FT-IR), yakin kzzll ötesi (NIR) ve Raman spektrometrelerin geniş uygulama alanları tartışllmıştır. Farmasötik ürünlerde yapılan sahtecilikler sonucunda, genel refah için bir tehlike haline gelen taklit, hileli, tahrif edilmiş ve standart altı farmasötik ürünlerin belirlenmesinde kullanılan bu portatif spektrometreler, titreşimsel ve saçılma spektroskopileri için kullanılmaktadır.

Gereç ve Yöntem: Çeşitli bilimsel makaleler ve kitaplar incelenmişs olup, geçmişten günümüze kadar olan süreçte, Fourier transform infrared (FT-IR), yakn kzzll ötesi (NIR) ve Raman spektrometrelerin farmasötik ürünlerin kalite kontrolü ve denetimi ile ilgili uygulamaları derlenmiştir.

Sonuç ve Tartışma: Hileli farmasötik ürünler özellikle gelişmekte olan ülkeler için önemli bir tehdit haline gelmiştir. Bu problem, farmasötik ürünlere olan güveni azaltabilmektedir. Bu makalede bahsi geçen portatif cihazların uygulanması, fitöfarmasötiklerin kalite kontrolünde tekniklerin daha erişilebilir, hızl, doğru, basit, hassas, sağlam ve daha da önemlisi, verimli olmasını sağlamaktadır.

Anahtar Kelimeler: Denetim, farmasötik ürünler, kalite kontrol, taşınabilir Fourier dönüşümlü infrared (FTIR) spektroskopisi, Yakin infrared (NIR) ve Raman Spektrometresi.

\section{INTRODUCTION}

Today, some of the greatest dangers and threats encountered by the pharmaceutical industry globally are issues of falsification, counterfeiting, adulteration, incapability and fraudulence. These issues have a negative impact on patients and are not beneficial for curing the target disease due to their reduced efficiency. This threat causes a loss in confidence in pharmaceutical products, health care providers and the health system in general.

According to the World Health Organization (WHO), antibiotics and anti-malarial drugs are the most reported adulterated pharmaceutical products which has led to anti-microbial resistance and likely drug-resistant infections. These falsified and substandard pharmaceutical products can be found in illegal street markets, illegal pharmacies, clinics, hospitals etc. and range from generic innovator medicines to expensive pharmaceutical products for cancer treatment and even includes inexpensive products used as analgesics. WHO defines falsified or substandard pharmaceutical products as medical products that do not contain any active pharmaceutical ingredients (API), while the incorrect ingredients include potato starch, corn starch or chalk etc. or an inadequate proportion of the active pharmaceutical ingredient. Some of these products are found to be toxic in nature, which are mostly produced in substandard and unhygienic environment/conditions, predominantly by unqualified personnel [1].

The usage of portable NIR, FT-IR and Raman spectroscopies are among the most appropriate methods for the detection and identification of organic and inorganic chemical constituents present in any pharmaceutical product. They provide information concerning the vibrational transitions of molecules or crystals with various sensitivities and specificities due to the different selection rules that 
govern infrared absorption and Raman scattering [2]. The information obtained from the vibrational spectroscopies is sometimes complementary to a degree depending on the symmetry degree of the molecules investigated [3-5]. Today, commercial handheld and portable FT-IR, NIR and Raman spectrometers are coupled with optical fibers or a proper instrument of measurement that allows spectral acquisition in reflection mode with a distance of about $1 \mathrm{~cm}$ and without any contact with the sample surface. Sequentially Shifted Excitation (SSE) is the technology that involves the principle of the Bravo spectrometer to acquire shifted Raman spectra while a suitable or desired algorithm allows the extraction of the spectral data in true Raman space.

This procedure was recently validated extensively for pharmaceutical applications, and is now widely accepted and used in routine analysis [6-15].

This review focuses on the advancement of rapid drug detection techniques using portable, miniaturized and handheld FT-IR, NIR and Raman spectrometers for inspecting the quality and quantity of pharmaceutical products. Moreover, some new characteristics of counterfeit, falsified and adulterated drugs are discussed and the ways of countering such products are given. For example, the usage of NIR models (Universal quantitative models) can be employed to examine pharmaceutical drugs with the same API made by different manufacturers. Finally, these portable spectroscopic techniques have good specificity, robustness, linearity, precision and accuracy [16, 17].

\section{SPECTROSCOPIC METHODS}

\section{Near Infrared (NIR) Spectroscopy}

The NIR region was first discovered by Herschel over 200 years ago, the region lies between 780 $2500 \mathrm{~nm}$, and is located between the red band of the visible light and the mid-infrared region. The obtained NIR spectrum is a result of molecular vibrations which comprise of combinations of fundamental vibrations and overtones of hydrogen bonds such as $\mathrm{O}-\mathrm{H}, \mathrm{C}-\mathrm{H}$ and $\mathrm{N}-\mathrm{H}$ [18]. This technique enables quick analysis for a wide range of materials, which have the possibility of having a large number of physicochemical parameters and chemical composition of many formulations. Many physicochemical parameters of pharmaceutical products can be analyzed quantitatively using NIR spectroscopy such as particle size, hardness, dissolution rate compaction force and water content among others [19-26]. For the last two decades, portable and miniaturized NIR spectroscopy has been utilized to provide numerous possibilities in industrial and pharmaceutical applications. It is a rapid technique, whereby FT-NIR can record a spectrum within only a few seconds. One of the advantages of this technique is the non-destructive method of the analysis, which means that analysis can be conducted with minimal sample preparation or sometimes no sample preparation. This facilitates the avoidance of steps that are responsible for errors. It also enables the measurement of packaged samples via package material [27] . 
Bei et al. [28] applied an orthogonal approach using handheld NIR, portable FT-IR and portable Raman analyzers which were coupled to offline chemometric data analysis to quickly distinguish different producers of domestic and imported oxcarbazepine drugs found in the Chinese market in a quality controlled laboratory setting. API of the synthesized pharmaceutical product as well as the starting materials, solid dosage forms and coatings were analyzed using an orthogonal approach. The results of the FT-IR, Raman and NIR were found to be in conformity to each other and constitute sources of cross-validation within the scope of this study. All three portable and handheld analyzers employed the advantages of utilized spectroscopic techniques for their potential in assisting and complementing regulatory bodies in adopting efficient, innovative and effective solutions.

Plugge et al. [29] reported that NIR spectroscopy coupled with a polar qualification system is a substantial method for differentiating similar pharmaceutical substances which only differ slightly in terms of physical or chemical characteristics. One of the applications of this powerful coupling is the more precise selection and definition of starting materials involved in the synthesis of medicinal products and its application in blending validation.

Vakili et al. [30] reported that quality control tools used in assessing the quality of printable orodispersible formulations have yet to be defined. In study, four different orodispersible formulations, consisting of two slightly soluble drugs, prednisolone and levothyroxine, were synthesized by piezoelectric inkjet printing using two different edible substrates. A compact miniaturized and handheld NIR device with the range of 1550-1950 nm was utilized for the quantitative determination of drugs in the printed formulations. The spectral data was further treated with Savitzky-Golay filtering, mean centering and third derivative approach. Orthogonal partial least squares (OPLS) regression and principal component analysis (PCA) were used to create predictive models for the quality control of the printed dosage formulations. The actual dose present in each formulation was confirmed using high performance liquid chromatography (HPLC) for levothyroxine (0.15-0.86 $\mathrm{mg}$ with $\left.\mathrm{R}^{2}=0.999\right)$. It was found that the model has the ability of to predict and cluster the drug formulations using both $\mathrm{Q}^{2}$ and $\mathrm{R}^{2} \mathrm{Y}$ values in the range of 0.94-0.99.

Many other international institutions are aware of the considerable potential of the NIR technique particularly when using handheld and miniaturized devices for process monitoring and quality control in the pharmaceutical industry [31].

In addition, Dreassi et al [32] reported the integrated quality control of cefuroxime axetil drug, through the identification of starting materials and the API, and proceeded with controlling the drug ingredients. For the quality control, discriminant analysis (DA) was applied to both the PCA scores and the original spectral data. On the other hand, cluster analysis (CA) was also discussed in the research, which was also applied for the PCA scores. Both methods (DA and CA) gave veritable information 
concerning the identification of different intermediates in the production cycle. They can as well be used to differentiate between two similar and related granular types of Cefuroxime axetil.

\section{Fourier Transform Infrared (FT-IR) Spectroscopy}

Infrared spectroscopy is a useful tool for the identification of drugs [33]. It is also useful in quantitative analysis as it allows for the continuous monitoring of spectral baseline and aids in the simultaneous analysis of numerous parameters of the same sample [34]. Among its greatest advantages is the ability to study the sample at virtually any given state. As a result of advances in instrumentation, numerous new techniques were designed and introduced in order to test and identify the samples that were formerly considered difficult $[35,36]$.

The infrared region is at around $700 \mathrm{~nm}\left(14.285,71 \mathrm{~cm}^{-1}\right)$, which is immediately beyond the visible region. Wave number is generally used to indicate the infrared spectral region. The radiation energy of this region ranges between $48 \mathrm{kjmol}^{-1}$ at 2,500 nm and $2.4 \mathrm{kj} \mathrm{mol}^{-1}$ at 50,000 nm. Two units can be used in such vibrational spectroscopy; $\mathrm{cm}^{-1}$ (wave number) and $\mathrm{nm}$. The unit of choice depends on the type of the spectrometer (i.e dispersive vs Fourier Transform) and in order to avoid large numbers whereby $\mathrm{nm}$ is used. The mathematical relationship of these two units is given below.

$$
\left[\mathrm{Cm}^{-1}\right]=1 /[\mathrm{nm}] \times 10^{-7}
$$

The development of Fourier Transform infrared (FT-IR) has to a true revolution in the area of IR spectrometry, due to its positive impact. It is a fast and accurate analytical technique which provides impressive qualitative information for gaseous, liquid and solid samples. The use of IR has grown immensely in recent years. The importance of FT-IR was originally intended to identify and learn about functional groups present in a particular chemical sample, but in recent years, it has been widely used for the identification, evaluation, quality control and inspection of pharmaceutical products for the purpose of drug design and minimizing the undesired alteration of products [37-42].

The miniaturization of vibrational spectrometers has emerged in the past decade, but the real handheld FT-IR, NIR and Raman scanning spectrometers have only recently become readily and commercially available. This development is due to advances in microelectromechanical systems (MEMS) and recently, they have had a significant impact on the analytical techniques as well as on-site analysis. Their applications have been demonstrated in many fields, such as terror defense, homeland security, forensic investigations and in some drug agencies.

Sorak et al. [43] reported that the recent miniaturization of infrared and Raman spectrometers has led to substantial progress in analytical techniques. The usage of handheld and portable infrared spectrometers resulted in a reduction in instrument size and increased measurement performance. These 
portable devices have had an impact on quality control as well as process control. They can also be used to calibrate the handheld and portable systems provided, while the qualitative and quantitative results for certain solid and liquid samples of these handheld spectrometers are evaluated according to their comparability with other laboratory instruments and their suitability for field and on-site measurements are also compared. The results showed that the application of these handheld devices for on-site purposes will open up a wide range of new applications of such devices in various industrial branches and hence will revitalize the application of vibrational spectroscopy in quality control, identification, process control and inspection in the near future.

Moreover, FT-IR was designed for quick and direct analysis of acetylsalicylic acid (ASA) in various pharmaceutical drugs [44]. The API were determined and compared using conventional $\mathrm{KBr}$ spectra. Two chemometric approaches, principal components regression $(\mathrm{PCR}+)$ and partial least squares (PLS), in addition to Beer-Lambert's law were employed in data processing. Additionally, the researchers studied the possibility of applying the Beer-Lambert law to determine the quality of ASA in pharmaceutical products at a wave number of $1,605.49 \mathrm{~cm}^{-1}$, and similarities within the results were observed suggesting the application of $\mathrm{PCR}+$ technique due to a smaller value of relative standard deviation (RSD; <3.0\%).

Fourier transform infrared spectroscopy was applied for rapid and direct measurement of vitamin $\mathrm{C}$ (ascorbic acid) and Vitamin $\mathrm{B}_{7}$ (biotin) in various pharmaceutical products. The APIs in drug preparation were best determined by comparing conventional $\mathrm{KBr}$ spectra. The data was also processed using chemometric and Beer-Lambert approaches [45]. Vitamin $\mathrm{C}$ is an essential nutrient for a wide number of primates [46], which include $20 \%$ of the mammalian group, as well as small number of other species such as certain birds, fish and guinea pigs. Biotin is soluble in water and composed of ureido (tetrahydroimidazolone) ring fused with tetrahydrothiophene ring.

Antimalarial drugs such as artesunate tablets were among the most counterfeited pharmaceutical products. A newly introduced analytical technique which comprises the combination of ATR (Attenuated Total Reflection)-FTIR imaging, Raman spectroscopy, and Spatially Raman Spectroscopy (SORS) was developed to screen and characterize genuine and adulterated artesunate tablets.

Vibrational spectroscopy shows the chemical constituents present in the tablets by using the complementary properties of FT-IR imaging and Raman scattering allowing the characterization of the surface and overall compositions of the tablets. The advantages of this analytical technique, point to its potential to be included and used in analytical methods for the investigation of falsified and fake drugs or medicines [47].

The quality control assurance of pharmaceutical products such as ginseng has significant importance for consumer safety $[48,49]$. Ginseng is an expensive and precious herb normally adulterated with less expensive products. Its quality control and inspection is strongly needed and recommended 
due to its high degree of consumption and commercial importance. It can be consumed in powder, capsule, tea, or softgel forms [50]. Extracts of American ginseng (The root of Panaxquinque folius), Notoginseng (the root of Panax notoginseng) and Asian ginseng (the root of Panax ginseng) were distinguished using conventional FTIR spectroscopy (ID-FTIR) and the two dimensional correlation FT-IR using thermal perturbation. Moreover, the differences in their peak intensity were observed at about 1640, 1416, 1372 and $1048 \mathrm{~cm}^{-1}$ in the FTIR results of these species to ease their differentiation and identification [51].

A pseudopolymorphic and two polymorphic crystal forms of local anesthetic agent hydrozxyprocaine hydrochloride were characterized and analyzed using spectroscopy (FTIR, SSNMR spectroscopy, FT-Raman), water vapor sorption analysis, thermal analysis (hot stage microscopy, thermogravimetry and differential scanning calorimetry) and powder x-ray diffractometry [52].

Nitrofurantoin and Ampicillin in both the hydrate and hydrous forms were characterized using $\mathrm{x}$ ray diffractometry (XRD), thermogravimetric and differential thermal analysis (TG/DTA) and powder DRIFTs. Among the analytical tools used, only DRIFTs indicate the formation of H-bonds of the anhydrous drug constituents and the presence of crystalline water taken up from the atmospheric moisture, which shows significant absorption from 3,500-3,700 $\mathrm{cm}^{-1}$ that corresponds to crystalline water. The FTIR spectral results of the hydrate and anhydrous forms of the nitrofurantoin also show significant differences [53].

FT-IR spectrometry is applied for the analytical quantification of various pharmaceutical formulations with commercial software and chemometric approaches. It is a simple, quick and precise method when compared to chromatographic methods used previously. The quantification is completed within 15-16 minutes, including sample preparation and the spectral result acquisition [54].

Finally, FT-IR is a quick, non-destructive and reliable analytical technique and when coupled with chemometrics, it can be a powerful tool in the pharmaceutical industry. It is also being used in the analysis of herbal medicine and can also be applied in the quality control of pharmaceutical products and to inspect possible counterfeiting [55].

\section{Raman Spectroscopy}

The first discovery of a new kind of secondary radiation which called 'Raman' scattering, was by Raman and Krishnan in the year 1928. The instrumentation was further developed when using this principle through advances in optoelectronics and photonics, as well as the rapidly expanding range of usage and applications. Raman spectrometers have evolved continuously over the decades [56]. Based on history, the evolution of Raman tools were also augmented through numerous discoveries of different phenomena rather than the basic Raman Effects such as resonance Raman (RR), surface-enhanced Raman scattering (SERS). It was proven to be a useful instrument in numerous fields such as 
pharmaceuticals, process control, in vivo biomedical studies, environmental sciences, catalysts, pigments, archeology, glasses and forensic sciences [57].

The spectral analysis of pharmaceutical products using Raman spectroscopy provides more benefits than mid or NIR spectroscopy (the comparision between Raman and IR spectroscopies are summerized at Table 1). As a result of its scattering technique, it does not require a reference light path as in IR or NIR. This allows remote sampling and is also amenable to fiber optics. A typical Raman measurement for a single scan can give spectral data in the range of $4000-40 \mathrm{~cm}^{-1}$ and a finger print range of 4000 and $400 \mathrm{~cm}^{-1}$. Some chemical groups give strong Raman signals such as $\mathrm{C}=\mathrm{S}$, which produces a signal in the range of $1000-1250 \mathrm{~cm}^{-1}$ and $\mathrm{C}-\mathrm{Cl}$ with a signal around $500-800 \mathrm{~cm}^{-1}$. Certain polar groups such as $\mathrm{O}-\mathrm{H}$ give a weak signal as opposed to IR, which gives a strong signal. As an example of Raman spectrum, Curcumin shows characteristic groups and is interpreted as having groups such as aromatic $\mathrm{C}=\mathrm{O}$ stretching signal at $1626 \mathrm{~cm}^{-1}$ and $\mathrm{C}=\mathrm{C}$ stretching signal at $1601 \mathrm{~cm}^{-1}$ [58].

Table 1. Comparison between Raman and Infrared (FT-IR and NIR) spectroscopies

\begin{tabular}{|c|c|}
\hline RAMAN Spectroscopy & Infrared Spectroscopy \\
\hline $\begin{array}{l}\text { It is due to the scattering of light by the vibrating } \\
\text { molecules }\end{array}$ & $\begin{array}{c}\text { It is the result of absorption of light by vibrating } \\
\text { molecules }\end{array}$ \\
\hline $\begin{array}{c}\text { The vibration is Raman active if it causes a change in } \\
\text { polarizability }\end{array}$ & $\begin{array}{c}\text { Vibration is IR active if there is change in dipole } \\
\text { moment }\end{array}$ \\
\hline $\begin{array}{c}\text { The molecule doesn't have to posses a permanent dipole } \\
\text { moment }\end{array}$ & $\begin{array}{l}\text { The vibration concerned should have a change in } \\
\text { dipole moment due to that vibration }\end{array}$ \\
\hline Water can be used as a solvent & $\begin{array}{l}\text { Water can't be used in IR due to its high intense } \\
\text { absorption in IR }\end{array}$ \\
\hline $\begin{array}{c}\text { Sample preparation is not very elaborate it can be in any } \\
\text { state }\end{array}$ & $\begin{array}{l}\text { Sample preparation is elaborate gaseous samples } \\
\text { can rarely be used }\end{array}$ \\
\hline Gives an indication of covalent character in the molecule & $\begin{array}{c}\text { Gives an indication of ionic character in the } \\
\text { molecule }\end{array}$ \\
\hline Cost of instrumentation is very high & Comparatively inexpensive \\
\hline
\end{tabular}

Without any sample preparation, Raman spectroscopy is able to perform non-destructive and noninvasive screening and analysis into the packaging and hence can keep the sample constituents intact in case of further analysis.

Raman spectrometers are composed of a laser light source, focusing optics and spectrographs that consist of detector and dispersity elements [59].

Nowadays, the Raman-based instruments are portable, handheld, miniaturized, cheaper, smaller and faster. Furthermore, the concept of analyzing real world samples from the production unit through to packaged containers has developed from being merely to a hypothetical proposition to the level of a 
well-established concept for the quality control and inspection of various pharmaceutical products [60, $61]$.

According to a study conducted for the measurement of some pharmaceutical products using portable Raman spectrometer with $785 \mathrm{~nm}$ excitation, the sample was further transferred into a small brass cylinder and the head of the spectrometer was set on top of a small brass cylinder to allow for the focusing of the laser beam into the sample. A wave number between $1800-400 \mathrm{~cm}^{-1}$ was then chosen to develop PLS-1 calibration for each of the active ingredients. This was done in order to demonstrate the performance of the portable Raman spectrometer for quality control and inspection of the qualitative and quantitative active ingredients [62].

Similar to NIRs, Raman spectroscopy has been tested and shown to be successful in portable and miniaturized units for the identification and detection of counterfeiting and falsification [63]. Raman spectroscopic techniques have become increasingly popular as a result of the invention of portable and miniaturized Raman devices [64].

Noonan et al. [65] developed a universal approach for models that can classify and categorize multiple drugs of interest in the presence of three cutting agents, some of them had high similarity to the drugs of interest. Based on the idea of the models developed they were opportune to cluster four drug surrogates successfully, namely lidocaine, benzocaine, norephedrine and isoxsuprine. They further expatiated the spectral acquisition by applying both rugged and home built, handheld and commercial devices as well as the preprocessing of the needed spectra before developing the model.

Loethen et al [66] also reported a method which was developed to rapidly screen a bread group of anti-infective agent, as a form of anti-conterfeit screening. They used only Raman spectra of the active pharmaceutical ingredients as reference point.

Rohleder et al. [67] demostrated the application of Raman spectroscopy during a study on antioxidative stability of cosmetic products formulations [68]. Larmour and Bell utilized the ultraviolet resonance Raman technique to ascertain the stability of some biopharmaceutical protein formulations.

The Raman spectroscopic technique can be applied in testing coatings as well as checking their falsification and counterfeiting. Witkowski et al. [69] compared the Raman spectra of an authentic and original coated tablet and that of a coated tablet under suspicion of adulteration. They realized that the major spectral features seen in both the two spectra were due to the presence of titanium oxide. Additionally, upon further inspection on the spectral data, another peak was observed in the Raman spectrum of the suspected adulterated and counterfeited coated tablet, which was not observed on the authentic and original coated tablet's Raman spectrum. Therefore, this study proved the counterfeiting in the sample tablet [70].

Tfayli et al. [71] showed the application of confocal Raman microscopy to determine the amount of drugs present in human skin. 
Finally, Raman spectroscopy has advantages for the diagnosis of various diseases that have been widely accepted in the health sciences. It has been applied in biomedicine to understand and identify the dynamics of nucleic acids. It can also be applied to detect and test human papilloma virus at its early stage, thereby enabling timely application of the correct medication for curing the disease. It can also help in the development of stroke-preventing medication and in the detection of squamous cell carcinoma, brain tumors, brain metastasis and lymph nodes metastasis through studying the histopathology of tissue [72-74].

\section{RESULT AND DISCUSSION}

A wide range of applications, chosen to demonstrate and show the high performance of portable and miniaturized NIR, FT-IR and Raman spectrometers for the inspection and quality control of pharmaceutical products, were explained and summerized in Table 2.

Table 2. Summary of some reviewed studies

\begin{tabular}{|c|c|c|}
\hline Device & Sample & Source \\
\hline NIF & $\begin{array}{c}\text { Four different orodispersible formulations, consisting of two } \\
\text { slightly soluble drugs, prednisolone and levothyroxine, were } \\
\text { synthesized by piezoelectric inkjet printing using two different } \\
\text { edible substrates }\end{array}$ & {$[30]$} \\
\hline NIF & $\begin{array}{c}\text { Quality control of cefuroxime axetil drug, through identifying the } \\
\text { starting materials and the API, and proceeded with the drug control }\end{array}$ & {$[32]$} \\
\hline FTIR & Vitamin C and Biotin & {$[44]$} \\
\hline $\begin{array}{c}\text { ID-FTIR and Two } \\
\text { dimensional correlation } \\
\text { FT-IR }\end{array}$ & $\begin{array}{c}\text { Extracts of American ginseng (The root of Panaxquinque folius), } \\
\text { Notoginseng (the root of Panax notoginseng) and Asian ginseng } \\
\text { (the root of Panax ginseng) }\end{array}$ & {$[49]$} \\
\hline $\begin{array}{c}\text { FTIR, SSNMR } \\
\text { spectroscopy, FT-Raman }\end{array}$ & $\begin{array}{c}\text { A pseudo polymorphic and two polymorphic crystal forms of local } \\
\text { anesthetic agent hydrozxyprocaine hydrochloride }\end{array}$ & {$[50]$} \\
\hline $\begin{array}{c}\text { X-ray diffractometry } \\
\text { (XRD), } \\
\text { Thermogravimetric and } \\
\text { Differential Thermal } \\
\text { Analysis (TG/DTA) and } \\
\text { Powder DRIFT }\end{array}$ & $\begin{array}{c}\text { Nitrofuraintoin and Amphicilline in both the hydrate and hydrous } \\
\text { forms }\end{array}$ & {$[51]$} \\
\hline $\begin{array}{c}\text { Raman spectroscopy } \\
\text { paman spectroscopy }\end{array}$ & $\begin{array}{c}\text { Anti-counterfeit rapid screening of some finished pharmaceutical } \\
\text { products }\end{array}$ & {$[64]$} \\
\hline $\begin{array}{c}\text { Raman microscopy } \\
\text { Anti-oxidative stability of cosmetic products formulations }\end{array}$ & {$[67]$} \\
\hline Determination the amount of drugs present in human skin & {$[69]$} \\
\hline
\end{tabular}


Today, substandard pharmaceutical products have become the greatest threat to the general well-being in developing countries. This can decrease the confidence of the pharmaceutical products and the health care in general. These techniques enable the quick monitoring, inspection and identification of adulteration of different pharmaceutical products.

The application and usage of these portable instruments make the techniques accessible, fast, reagent free (in some cases), simple and more importantly, efficient.

\section{REFERENCES}

1. World Health Organization. (2018). Substandard and falsified medical products, (143 rd session of the executive board).

2. Pérez-Alonso, M., Castro, K., Madariaga, J. M. (2006). Vibrational spectroscopic techniques for the analysis of artefacts with historical, artistic and archaeological value. Current Analytical Chemistry, 2(1), 89-100.

3. Duran, A., Jimenez De Haro, M., Perez-Rodriguez, J., Franquelo, M., Herrera, L., Justo, A. (2010). Determination of pigments and binders in Pompeian wall paintings using synchrotron radiation-high-resolution X-ray powder diffraction and conventional spectroscopychromatography. Archaeometry, 52(2), 286-307.

4. Nastova, I., Grupče, O., Minčeva-Šukarova, B., Kostadinovska, M., Ozcatal, M. (2015). Spectroscopic analysis of pigments and inks in manuscripts. III. Old-Slavonic manuscripts with multicolored rubication. Vibrational Spectroscopy, 78, 39-48.

5. Crupi, V., Allodi, V., Bottari, C., D’Amico, F., Galli, G., Gessini, A., Mariotto, G. (2016). Spectroscopic investigation of Roman decorated plasters by combining FT-IR, micro-Raman and UV-Raman analyses. Vibrational Spectroscopy, 83, 78-84.

6. Bitossi, G., Giorgi, R., Mauro, M., Salvadori, B., Dei, L. (2005). Spectroscopic techniques in cultural heritage conservation: a survey. Applied Spectroscopy Reviews, 40(3), 187-228.

7. Clark, R. J. (2006). Applications of R aman Spectroscopy to the Identification and Conservation of Pigments on Art Objects. Handbook of vibrational spectroscopy.

8. Miliani, C., Rosi, F., Daveri, A., Brunetti, B. G. (2012). Reflection infrared spectroscopy for the non-invasive in situ study of artists' pigments. Applied Physics A, 106(2), 295-307.

9. Lauwers, D., Hutado, A. G., Tanevska, V., Moens, L., Bersani, D., Vandenabeele, P. (2014). Characterisation of a portable Raman spectrometer for in situ analysis of art objects. Spectrochimica Acta Part A: Molecular and Biomolecular Spectroscopy, 118, 294-301.

10. Colomban, P. (2012). The on-site/remote Raman analysis with mobile instruments: a review of drawbacks and success in cultural heritage studies and other associated fields. Journal of Raman spectroscopy, 43(11), 1529-1535. 
11. Vandenabeele, P., Edwards, H. G. M., Jehlička, J. (2014). The role of mobile instrumentation in novel applications of Raman spectroscopy: archaeometry, geosciences, and forensics. Chemical Society Reviews, 43(8), 2628-2649.

12. Barone, G., Bersani, D., Jehlička, J., Lottici, P. P., Mazzoleni, P., Raneri, S., Larinà, G. (2015). Nondestructive investigation on the 17-18th centuries Sicilian jewelry collection at the Messina regional museum using mobile Raman equipment. Journal of Raman Spectroscopy, 46(10), 989995.

13. Conti, C., Botteon, A., Bertasa, M., Colombo, C., Realini, M., Sali, D. (2016). Portable Sequentially Shifted Excitation Raman spectroscopy as an innovative tool for in situ chemical interrogation of painted surfaces. Analyst, 141(15), 4599-4607.

14. Terao, W., Mori, T., Fujii, Y., Koreeda, A., Kabeya, M., Kojima, S. (2018). Boson peak dynamics of natural polymer starch investigated by terahertz time-domain spectroscopy and low-frequency Raman scattering. Spectrochimica Acta Part A: Molecular and Biomolecular Spectroscopy, 192, $446-450$.

15. Vagnini, M., Gabrieli, F., Daveri, A., Sali, D. (2017). Handheld new technology Raman and portable FT-IR spectrometers as complementary tools for the in situ identification of organic materials in modern art. Spectrochimica Acta Part A: Molecular and Biomolecular Spectroscopy, $176,174-182$.

16. Guidance document on the use of detection technologies and overview of detection technologies for drug safety, (2015).

17. Zou, W.-B., Yin, L.-H., Jin, S.-H. (2017). Advances in rapid drug detection technology. Journal of Pharmaceutical and Biomedical Analysis, 147, 81-88.

18. Herschel, W. (1800). Experiments on the refrangibility of invisible rays of the sun. Philosophical Transactions Of The Royal Society A: Mathematical, Physical And Engineering Sciences, 90, 255-326.

19. Jamrógiewicz, M. (2012). Application of the near-infrared spectroscopy in the pharmaceutical technology. Journal of Pharmaceutical and Biomedical Analysis, 66, 1-10.

20. Anderson, C. A., Drennen, J. K., Ciurczak, E. W. (2008). Pharmaceutical applications of nearinfrared spectroscopy. Practical Spectroscopy Series, 35, 585.

21. Siesler, H. W., Ozaki, Y., Kawata, S., Heise, H. M. (2008). Near-infrared spectroscopy: principles, instruments, applications. John Wiley \& Sons.

22. Agelet, L. E., Hurburgh Jr, C. R. (2010). A tutorial on near infrared spectroscopy and its calibration. Critical Reviews in Analytical Chemistry, 40(4), 246-260.

23. Workman, J. (1993). A review of process near infrared spectroscopy: 1980-1994. Journal of Near Infrared Spectroscopy, 1(4), 221-245.

24. Noda, I. (2006). Progress in two-dimensional (2D) correlation spectroscopy. Journal of Molecular Structure, 799(1-3), 2-15. 
25. Bista, R. K., Bruch, R. F., Covington, A. M. (2010). Vibrational spectroscopic studies of newly developed synthetic biopolymers. Biopolymers, 93(5), 403-417.

26. FDA Guidance for industry, (2004). PAT- a frame work for innovative pharmaceutical development. Manufacturing and quality assurance, pharmaceutical, in: CGMPs.

27. McClure, W. F. (2003). 204 years of near infrared technology: 1800-2003. Journal of Near Infrared Spectroscopy, 11(6), 487-518.

28. Bei M., Linbo W. (2015). An Application of Rapid Detection Technologies in a National Regulatory Laboratory Setting: Differentiating Imported and Domestic Drug Products of Oxcarbazepine Using Handheld Raman, Near Infrared, and Portable FTIR Analyzers. American Pharmaceutical Review , Featured-Articles/173075

29. Plugge, W., Van Der Vlies, C. (1996). Near-infrared spectroscopy as a tool to improve quality. Journal of Pharmaceutical and Biomedical Analysis, 14(8-10), 891-898.

30. Vakili, H., Wickström, H., Desai, D., Preis, M., Sandler, N. (2017). Application of a handheld NIR spectrometer in prediction of drug content in inkjet printed orodispersible formulations containing prednisolone and levothyroxine. International Journal of Pharmaceutics, 524(1-2), $414-423$.

31. Moffat, A. C., Trafford, A. D., Jee, R. D., Graham, P. (2000). Meeting the International Conference on Harmonisation's Guidelines on Validation of Analytical Procedures: Quantification as exemplified by a near-infrared reflectance assay of paracetamol in intact tabletsThe opinions expressed in the following article are entirely those of the authors and do not necessarily represent the views of either The Royal Society of Chemistry or the Editor of The Analyst. Analyst, 125(7), 1341-1351.

32. Dreassi, E., Ceramelli, G., Savini, L., Corti, P., Perruccio. P.L., Lonardi, S. (1995). Application of near-infrared reflectance analysis to the integrated control of antibiotic tablet production. Analyst, 120(2), 319-323.

33. Rock Ville. (1990). Pharmaceutical convention. In United States pharmacopoeia 22nd ed.

34. Bunaciu, A. A., Udristioiu, G. E., Ruţă, L. L., Fleschin, Ş., \& Aboul-Enein, H. Y. (2009). Determination of diosmin in pharmaceutical formulations using Fourier transform infrared spectrophotometry. Saudi Pharmaceutical Journal, 17(4), 303-306.

35. Stuart, B. (2005). Infrared spectroscopy. Kirk-Othmer Encyclopedia of Chemical Technology.

36. Skoog, D. A., Holler, F. J., Crouch, S. R. (2007). Instrumental analysis. Brooks/Cole, Cengage Learning Belmont.

37. Ahuja, S., Jespersen, N. (2006). Principles of spectroscopy and spectroscopic analysis in Wilson and Wilson's comprehensive analytical chemistry, in: Modern Instrumental Analysis, (pp. 111137). Elsevier

38. G.Brittain, H., David E.Bugay. (2006). In Infrared Absorption spectroscopy in spectroscopy of pharmaceutical solids. (pp. 235-265). Taylor and Francis. 
39. James R. Durig. (1980). Analytical Applications of FT-IR to Molecular and Biological Systems. University of South Carolina, Columbia, United States: NATO ASI Series.

40. Wartewig, S., Neubert, R. H. (2005). Pharmaceutical applications of Mid-IR and Raman spectroscopy. Advanced Drug Delivery Reviews, 57(8), 1144-1170.

41. Chan, K. L. A., Kazarian, S. G., Vassou, D., Gionis, V., Chryssikos, G. D. (2007). In situ highthroughput study of drug polymorphism under controlled temperature and humidity using FT-IR spectroscopic imaging. Vibrational Spectroscopy, 43(1), 221-226.

42. Bunaciu, A. A., Aboul-Enein, H. Y., Fleschin, S. (2010). Application of Fourier Transform Infrared Spectrophotometry in Pharmaceutical Drugs Analysis. Applied Spectroscopy Reviews, 45(3), 206-219. doi:10.1080/00387011003601044

43. Sorak, D., Herberholz, L., Iwascek, S., Altinpinar, S., Pfeifer, F., Siesler, H. W. (2012). New developments and applications of handheld Raman, mid-infrared, and near-infrared spectrometers. Applied Spectroscopy Reviews, 47(2), 83-115.

44. Bunaciu, A. A., Aboul-Enein, H. Y., Fleschin, Ş. (2006). FT-IR Spectrophotometric analysis of acetylsalicylic acid and its pharmaceutical formulations. Canadian Journal of Analytical Sciences and Spectroscopy, 51, 253-259.

45. Bunaciu, A. A., Bacalum, E., Aboul-Enein, H. Y., Elena Udristioiu, G., Fleschin, Ş. (2009). FTIR spectrophotometric analysis of ascorbic acid and Biotin and their pharmaceutical formulations. Analytical Letters, 42(10), 1321-1327.

46. McCluskey, E. S. (1985). Which vertebrates make vitamin C. Origins, 12(2), 96-100.

47. Deisingh, A. K. (2005). Pharmaceutical counterfeiting. Analyst, 130(3), 271-279.

48. Yang, P., Song, P., Sun, S.-Q., Zhou, Q., Feng, S., Tao, J.-X. (2009). Differentiation and quality estimation of Cordyceps with infrared spectroscopy. Spectrochimica Acta Part A: Molecular and Biomolecular Spectroscopy, 74(4), 983-990.

49. Ricci, C., Eliasson, C., Macleod, N. A., Newton, P. N., Matousek, P., Kazarian, S. G. (2007). Characterization of genuine and fake artesunate anti-malarial tablets using Fourier transform infrared imaging and spatially offset Raman spectroscopy through blister packs. Analytical and Bioanalytical Chemistry, 389(5), 1525.

50. Yap, K. Y.-L., Chan, S. Y., Lim, C. S. (2007). Authentication of traditional Chinese medicine using infrared spectroscopy: distinguishing between ginseng and its morphological fakes. Journal of Biomedical Science, 14(2), 265-273.

51. Aaltonen, J., Gordon, K. C., Strachan, C. J., Rades, T. (2008). Perspectives in the use of spectroscopy to characterise pharmaceutical solids. International Journal of Pharmaceutics, 364(2), 159-169.

52. Schmidt, A. C., Schwarz, I. (2005). Solid state characterization of hydroxyprocaine hydrochloride. Crystal polymorphism of local anaesthetic drugs, part VIII. Journal of Molecular Structure, 748(1-3), 153-160. 
53. Clarke, F. (2004). Extracting process-related information from pharmaceutical dosage forms using near infrared microscopy. Vibrational Spectroscopy, 34(1), 25-35.

54. Bunaciu, A. A., Udristioiu, G. E., Ruţă, L. L., Fleschin, Ş., Aboul-Enein, H. Y. (2009). Determination of diosmin in pharmaceutical formulations using Fourier transform infrared spectrophotometry. Saudi Pharmaceutical Journal, 17(4), 303-306.

55. Bunaciu, A. A., Aboul-Enein, H. Y., Fleschin, S. (2011). Recent applications of fourier transform infrared spectrophotometry in herbal medicine analysis. Applied Spectroscopy Reviews, 46(4), $251-260$.

56. Li, Y.-S., Church, J. S. (2014). Raman spectroscopy in the analysis of food and pharmaceutical nanomaterials. Journal of Food and Drug Analysis, 22(1), 29-48.

57. Mahadevan-Jansen, A. (2003). Raman spectroscopy: from benchtop to bedside. Biomedical Photonics Handbook.

58. Garrigues, S., de la Guardia, M. (2013). Non-invasive analysis of solid samples. TrAC Trends in Analytical Chemistry, 43, 161-173.

59. Cialla, D., März, A., Böhme, R., Theil, F., Weber, K., Schmitt, M., Popp, J. (2012). Surfaceenhanced Raman spectroscopy (SERS): progress and trends. Analytical and bioanalytical chemistry, 403(1), 27-54.

60. Dent, G., Smith, G. (2005). Modern Raman spectroscopy: a practical approach. Wiley.

61. Paudel, A., Raijada, D., Rantanen, J. (2015). Raman spectroscopy in pharmaceutical product design. Advanced Drug Delivery Reviews, 89, 3-20.

62. Smith, E., Dent, G. (2013). Modern Raman spectroscopy: a practical approach. John Wiley \& Sons.

63. Roggo, Y., Degardin, K., Margot, P. (2010). Identification of pharmaceutical tablets by Raman spectroscopy and chemometrics. Talanta, 81(3), 988-995.

64. Hajjou, M., Qin, Y., Bradby, S., Bempong, D., Lukulay, P. (2013). Assessment of the performance of a handheld Raman device for potential use as a screening tool in evaluating medicines quality. Journal of Pharmaceutical and Biomedical Analysis, 74, 47-55.

65. Noonan, K. Y., Tonge, L. A., Fenton, O. S., Damiano, D. B., Frederick, K. A. (2009). Rapid classification of simulated street drug mixtures using Raman spectroscopy and principal component analysis. Applied Spectroscopy, 63(7), 742-747.

66. Loethen, Y. L., Kauffman, J. F., Buhse, L. F., Rodriguez, J. D. (2015). Rapid screening of antiinfective drug products for counterfeits using Raman spectral library-based correlation methods. Analyst, 140(21), 7225-7233.

67. Rohleder, D. R., Kocherscheidt, G., Gerber, K., Kiefer, W., Köhler, W., Möcks, J., Petrich, W. H. (2005). Comparison of mid-infrared and Raman spectroscopy in the quantitative analysis of serum. Journal of Biomedical Optics, 10(3), 031108. 
68. Darvin, M. E., Sterry, W., Lademann, J. (2010). Resonance Raman spectroscopy as an effective tool for the determination of antioxidative stability of cosmetic formulations. Journal of Biophotonics, 3(1-2), 82-88.

69. Witkowski, M. R. (2005). The use of Raman spectroscopy in the detection of counterfeit and adulterated pharmaceutical products. American Pharmaceutical Review, 8, 56-62.

70. Gala, U., Chauhan, H. (2015). Principles and applications of Raman spectroscopy in pharmaceutical drug discovery and development. Expert opinion on drug discovery, 10(2), 187206.

71. Tfayli, A., Piot, O., Pitre, F., Manfait, M. (2007). Follow-up of drug permeation through excised human skin with confocal Raman microspectroscopy. European Biophysics Journal, 36(8), 10491058 .

72. Franzen, L., Selzer, D., Fluhr, J. W., Schaefer, U. F., Windbergs, M. (2013). Towards drug quantification in human skin with confocal Raman microscopy. European journal of pharmaceutics and biopharmaceutics, 84(2), 437-444.

73. Downes, A., Elfick, A. (2010). Raman spectroscopy and related techniques in biomedicine. Sensors, 10(3), 1871-1889.

74. Puviarasan, N., Arjunan, V., Mohan, S. (2002). FT-IR and FT-Raman studies on 3aminophthalhydrazide and $\mathrm{N}$-aminophthalimide. Turkish Journal of Chemistry, 26(3), 323-334. 